\title{
Theoretical Logic and Forward Path of Chinese Opening-Up Strategy
}

\author{
Yan $\mathrm{Wei}^{1,2}$
}

1.School of Economics and Management, Minjiang University, Fuzhou, Fujian 350108; 2. NanChang University Center of Central China Economic Development

Research ,NanChang,Jiangxi 330031

Key Words: Forward Path; Opening-up along the Borders; Unbalanced Development; Progressive Propulsion

\begin{abstract}
.
China's opening strategy proceeds in phases, moving progressively from economic zones, open-up along the coast and along banks of major rivers and then on the national borders. For different value system we get different evaluation of opening strategy and its performance, a Chinese style criterion and evaluation system are needed. Based on the survey of literature, we draw conclusions on Chinese opening-up strategy and its development path.

The exploration on regional opening strategy in China was dated from the open-door to the outside world in the eastern coastal regions in the end of 1970s. At the beginning, some coastal regions represented by Shenzhen, Zhuhai, Xiamen and Shantou were listed as special economic zones and they took the lead to implement the opening-up policy. From oceans to rivers, they were expanded to edgewise. Afterwards, 14 coastal cities, including Dalian, Qinhuangdao, Lianyungang and Nantong, were opened successively. The opening-up strategy was developed with the gradient of coastal regions, riverside regions and edgewise regions. The strategy was promoted by staging and stepping. Such a process not only included the exploration and innovation of opening-up theory, but also had the solid foundation of opening practice. The Chinese opening-up strategy not only provided reference of effective integration in industrial system transfer and inheritance opportunity in the world, but also contributed a successful case for rapid non-equilibrium development in regional economy.
\end{abstract}

\section{Coastal Opening-up Strategy: The Starting Point of Chinese Economic Opening Strategy}

In a sense, the exploration of Chinese reform and open-up strategy began with four special economic zones(Shenzhen, Zhuhai, Shantou and Xiamen). The initial idea of economic opening in China was to construct and open there economic supporting areas in coastal regions, namely Yangtze River Delta, Pearl River Delta and Circum-Bohai Sea Region. In the specific practical process, Shenzhen, Zhuhai, Shantou and Xiamen were chosen as special economic zones to explore coastal opening practically. With the breakthrough and test fields, it promoted the development of Chinese market economy, promoted the prior development in cities and regions through construction of coastal special economic zones, and formed regional differences through non-balanced development strategies, so as to create special 
economic areas. Objectively, coastal open regions under special policies could attract lots of domestic and overseas capital, technology and advanced management experience in coastal opening areas effectively, forming the growing pole effects. The efficient differences inevitably would promote unbalance development between regions, so as to realize the gradient radiation effects between developed areas and underdeveloped areas and finally realize efficiency promotion and economic prosperity in these areas. With the rapid economic development in coastal areas, national economic strength was thus enhanced rapidly. Meanwhile, with the development and expansion of gas in horizontal economic areas, such as economic development speed, quality and scale, mainland economy and edgewise economy, special zone construction became the practical starting point in Chinese coastal opening-up strategy.

\section{Edgewise Opening-up Strategy: Spatial Promotion of Economic}

\section{Opening-up Strategy}

From the perspective of open-door to the outside world, the essence of economic appeal in coastal and edgewise opening-up strategy is consistent, but their form of realization is slightly different. In 1992, the publication of the Notification on Further Opening Four Border Cities by the State Council, Including Heihe, indicated that Chinese economic opening-up strategy has been promoted to the edgewise opening-up policy. Beginning from Amur River in Heilongjiang in the north to Dongxing in Guangxi in the south, edgewise opening-up presented dotted distribution from north to south and opened a length of $22000 \mathrm{~km}$ of land route boundary, including Heilongjiang, Jilin, Liaoning, Inner Mongolia, Gansu, Xinjiang, Tibet, Yunnan and Guangxi, and bordered on 14 countries, including Russia, North Korea, Mongolia, Kazakhstan, Tajikistan, Kyrgyzstan, Pakistan, Burma, Laos and Vietnam, etc. Now it has 13 cities and towns (including Heihe in Heilongjiang, Huichun in Jilin, Ruili in Yunnan, and Pingxiang in Guangxi), as well as 232 land border ports. The opening area is about 740000 square kilometers.

The edgewise opening-up policy held multiple functional targets and heavy responsibilities of practical exploration. From the perspective of economic development, on the one hand, the edgewise opening-up policy tried to relieve the contradiction of too large regional development differences among edgewise, coastal regions and hinterland caused by high-speed non-balanced development. On the other hand, it also targeted to generalize and practice coastal opening experience. From the macroscopic perspective, edgewise opening-up policy was more than the spatial extension of coastal openness, but also contained regional economic integration, common prosperity, and expansion of coastal opening-up theory, etc. After implementing the edgewise opening-up policy, Chinese border regions acquired the faster development, but relative to eastern coastal regions, economic growth speed and total quantity between them still had a large gap, presenting the expanding tendency.

\section{From Coastal Opening-up Policy to Edgewise Opening-up Policy: Connection and}

\section{Expansion of Chinese Opening Path}

With the comprehensive expansion of coastal opening-up policy, riverside opening-up 
policy and edgewise opening-up policy in depth and width, every opening areas gathered in lines in the gradually in-depth expansion process, forming the connection and expansion of Chinese opening-up explorative paths. Finally, it realized regional opening-up to overall opening-up. During the process, we should treat with multi-dimensional transnational cooperation in edgewise regions systematically, combine edgewise opening-up with coastal opening-up to explore regional cooperation with characteristics of China's opening up, and define time logic and spatial sequence of coastal opening-up and edgewise opening-up gradually and define that coastal opening-up should be the precondition and condition based on it. Edgewise opening-up belonged to promotion and development. Both of them should be mutually supplemented to promote benign economic circulation. After the special economic zones with testing prosperity were established, it has been developed to more coastal regions or even expanded to riverside region and edgewise regions to form an integrity. This should be the specific target and selective path for China to implement the opening-up strategy.

\section{Comprehensive Evaluation of Chinese Economy on the Opening-up Strategy}

The opening-up strategy made China establish the multi-level and all-round opening system with "special economic zones-coastal regions-riverside regions-edgewise regions”, but it didn't form a set of indicator system that had comparability and generalization and also could make a comprehensive comparison on regions. It may have obvious defects to measure national and regional opening degree, opening scale and opening efficiency only by using GDP and GDP per capita or FDI, etc. These indicators are static and isolated. Moreover, how to measure changes before and after regional opening, how to separate opening driving of economic growth, and how to master efficiency difference of regional economic growth modes should be depended on reliable, controllable and comparable indicator system. Nowadays, the trade-oriented economic openness concept is used to measure opening efficiency. The so-called regional economic openness is a degree, showing that within certain regional range, commodities of economic entity and production elements(including capital, technology and labor force) participate in production and consumption activities in other regions. It not only covers commodity trade measurement, but also gets involved in service trade, capital, financial openness and productive international degree, etc. It has the favorable operability and comparability. Of course, indicator system can't be applied mechanically. It must have a process of reference, attempt, modification and expansion, let alone Chinese coastal opening-up, edgewise open-up theories and practical explorative fields.

International popular economic openness indicator refers to foreign trade for existence degrees, namely it refers to the specific value between total import and export trades and domestic GDP. Such a method is intuitive and easy to measure, thus it is widely applied. In 1990s, overseas scholars also proposed lots of new methods, including Dollars (Dollars, 1992), Sachs_-Warner (Sachs\& Warner, 1995) and Edwards (Edwards, 1998), and so forth.

Dollars uses actual practice of commodities and price derivative degree under trade opening conditions to measure regional economic openness. Meanwhile, by making a comparison on actual prices in different countries, it acquires relative economic openness in these countries, so as to establish the multi-dimensional economic openness indicator system. 
Sachs-Warner is a relatively rough measurement and it applies "binary system" to measure. In other words, trade openness degrees in various countries are divided into openness and non-openness. Conditions for trade openness can be divided into five aspects. If a country conforms to any one of them, the country belongs to non-open trade country. On the contrary, if a country doesn't conform to any of them, the country is an open trade country. Edwards uses existing nine economic openness measurements to form a kind of new measurement method. In essence, Edwards summarizes, concludes and uses achievements of other people. The creativity is lower, but accuracy of Edwards is higher than any method, thus it is widely believed that Edwards was one of creative achievements in measurement methods in 1990s. The studies on domestic openness were dated from post-implementation of opening-up policy. Luo Long(1990)[15] tried to use foreign trade and division of labor to establish a set of measurement indicators for Chinese open-up to the outside world. Pei Changhong(2015) continued the study and further studied relevant developmental indicators in Chinese opening economy during the "13th Five-year Plan" under the new normal by considering new opening-up value orientation contained in Chinese opening-up policy on the basis of original indicators. All of these attempts are important theoretical exploration on Chinese opening-up strategy. However, in the current practical application process, there is no relatively measure system. For the efficiency measurement of Chinese coastal opening-up and edgewise opening-up, the interference factors are more complicated than relatively successful international coastal opening-up cities, thus the opening efficiency measurement is more difficult.

\section{Conclusions}

To sum up, the opening study on Chinese "special economic zones-coastal regions-riverside regions-edgewise regions has acquired considerable experience achievements, but it is far away from maturity. Opening history limit, opening regional limit and opening degree limit increase limitation of the study to some extent. Opening theories in economic market with Chinese characteristic in exploration and pure western economic system have heterologous differences, resulting in shortage of uniform methodology foundation on some issues and phenomena.

\section{Acknowledgments}

[Fund project] Youth Project of National Social Science Foundation(15CJ L013); Jiangxi Social Science Planning Project(16JY21)

\section{References}

[1] Li Guohai and Qi Duojun, Comparison between Western Development and Coastal Opening-up Legal Environmental Construction[J], Journal of Wuhan University(Social Science Version), 2002, (02): 151-157;

[2] Liu Wei and Mao Shoulong, Logical Governmental Innovation and Limit Government[J], Academic Circles, 2014(04): 40-49; 
[3] Fu Jinpeng and Yang Jijun, Sustainability of Local Governmental Innovation in China: Influence Factors and Countermeasures[J], Theoretical Guidance, 2010, (12): 14-16;

[4] Wu Chuanbiao, Quantitative Research on Urban Tourism Development-Based on 14 Coastal Cities in China[J], Tourism Forum, 2009(05): 685-689

[5] Jing Xueqing, Comparison and Evaluation on Urban Utilization FDI of Chinese Coastal Opening-up[J], Social Sciences in Guangdong, 2011, (03): 27-33;

[6] Tao Yitao, From Coastal Opening-up to Edgewise Opening-up-Significance on Opening Expansion and Several Questions Concerned by Kashgar Special Economic Zone Development[J], Journal of Shenzhen University(Humanistic Social Science Version), 2013,(1): 88-93;

[7] Lv Yusheng, “Pan-Beibu Gulf” Industrial Cooperation Discussion in “One Belt and One Road” Construction[J], Academic Forum, 2016(07): 36-41;

[8] Liu Siyao and Liu Zhi, Discussion on Edgewise Opening Mode under Regional Economic Integration[J], Thought Line, 2012,(01): 84-86;

[9] Luo Long, Dynamic Analysis of Openness Changes in the Great Country[J], Economic Study on Quantity Economic Technology, 1990, (01): 16-20

[10] Pei Changhong, Performance Evaluation of Expanding Openness under New Normal of Economy[J], Economic Study, 2015, (04): 4-20 